\title{
Physics in Africa
}

\section{Rabia Salihu Sa’id(1), Ibiyinka Fuwape, Alain Moise Dikandé(i), Jamal Mimouni, Francis Hasford (1), Delia Haynes (D), Igle Gledhill (1), George Amolo (D, Omololu Akin-Ojo and Nashwa Eassa}

\begin{abstract}
Africa tends to be isolated and sometimes forgotten when it comes to scientific research and in particular physics. But the region has great potential, being home to the youngest population in the world, and despite a variety of issues, there has been steady, albeit uneven progress towards establishing a scientific infrastructure. Ten African researchers discuss the diverse challenges and opportunities faced by physicists across the continent.
\end{abstract}

\section{Three challenges of physics in Africa} Rabia Salihu Sa'id The challenges of physics in Africa, from what I have read and from conversations with fellow physicists from other African countries, are many. First, there is the challenge of numbers: there are few physicists engaged in research and in academia. This is perhaps because of a lack of research institutes and industry that would otherwise require people with a $\mathrm{PhD}$ or master's degree in physics. Using my university and my department as an example, and starting at the entry level and admission phase, one notices that most of the students admitted in the Bachelor of Science in physics programme had actually applied to study medicine. However, the medical school has a limited number of places so, generally, applicants who do not secure admission into the medical school are distributed into the single honours degree programme of physics, chemistry, biology and related fields. Because the applicants have the requisite academic entry requirements for the medical school, they are usually brilliant students, but since physics is not their first choice, they change career path after the bachelor's degree.

Second, there is the challenge of catch-up. Many African institutions and universities lack the requisite facilities to conduct research at the fast pace that research is conducted elsewhere. I encountered this situation in 2012 when I sent a research paper for a conference. I had studied single scattering by particles of dust aerosols. I received feedback that researchers have moved further from single scattering into multiple scattering, and my paper would be accepted if I scaled it up to include multiple scattering. At the time I did not have the facilities and modelling capability to scale up my research at my institution.

Third, there is the challenge of the paucity of research institutes and industry, which limits job opportunities for physicists to teaching in secondary schools and universities. Bachelor of Physics graduates who do not want to teach usually opt to work in revenue services or banks. These institutions gladly employ them because physicists have better affinity with numbers. This set of physicists then go on to pursue higher degrees in courses other than physics, opting for management courses that are more suited to their chosen career paths.

\section{Challenges facing Nigerian researchers} Ibiyinka Fuwape As a mentor to many young researchers within Nigeria and leader in academia, I see many early career scientists struggle to fit into a world not ready to accept them. It is a multifaceted challenge that has left many disoriented about academia. One major challenge is to be accepted based on what we - scientists working and living in Africa - have to offer and not our nationality. In my experience, editors may reject manuscripts by African researchers, only to later accept and publish similar work by other researchers. It sends a message that our knowledge and hard work is not enough to get us a seat at the table.

Access to many global grants including APC (article processing charge) waivers are tied to GDP (gross domestic product).
After the rebasing of Nigeria's GDP in 2008 , we were locked out of many global opportunities. This has left us out of the open access discussion because Nigerian researchers are mostly self-sponsored; hence, the costs of publications are highly prohibitive. Access to participate at conferences has also been restricted, as countries routinely decline visas, even when the applicant is fully funded by reputable organizations. Internally, researchers face poor pay, infrastructural challenges (irregular power supply, unsteady internet connectivity, basic research equipment), and fast-changing educational policies. These have led many Nigerian researchers to migrate to developed countries.

\section{Physics in sub-Saharan Africa}

Alain Moise Dikandé I have been told, "Our University does not need excellent researchers; the priority here is teaching, and as such we are looking for dedicated teachers, not ambitious ones who dream of the Nobel Prize." This sentence reflects the way our institutions have little concern for research, the priority being teaching. Physicists in Cameroon, and probably in most African countries in general, with the exception of South Africa and certain North African countries (Egypt, Tunisia and Morocco), work in this rather singular context, which requires self-denial and extreme passion to keep faith in research.

In addition to political disinterest in science and a hostile social environment, dominated by cultural beliefs portraying science as magic, in my experience physicists in sub-Saharan Africa also have to contend with contempt from their peers in developed countries - and sometimes even more so their colleagues in relatively more favoured African countries. Furthermore, with few exceptions, international organizations are generally not interested in research projects on the continent that do not fall in the scope of what they believe to be the priority for Africa (food security and health, or sometimes projects related to mining). In the context of such frictions, the temptation to drop out is certain and unfortunately represents the path that most talented researchers are following, to the detriment of the progress of research on the continent. 
That said, we must recognize an evolution in the mentalities of political powers, which seem to realize the stakes of science in a context as competitive as the one we live in today. Some sub-Saharan countries, including Cameroon, are taking initiatives, still timid but appreciable, to encourage research - the consequence of the progressive involvement of researchers in the management of the country's academic bodies. It is to be hoped that they remain mindful of the expectations of their colleagues.

\section{Bright spots amid uneven progress} Jamal Mimouni Can it be said that physics and astronomy are witnessing a boom in recent years in Africa? I would like to answer in the affirmative, especially in astronomy where quite a few bright spots have appeared, such as in Ethiopia with the Entoto Observatory and Research Centre, in Morocco with the Oukaimeden Observatory (Z. Benkhaldoun, Nat. Astron. 2 352-354; 2018) near Marrakech, and others. In South Africa, the SALT (Southern African Large Telescope) and the SKA (Square Kilometre Array) projects are a locomotive for the countries in the Southern region.

Other bright spots in physics are the legacy of the African School of Fundamental Physics and Applications (ASP), which has held its annual meeting in a different location every year since 2010 , and the AIMS (African Institute for Mathematical Sciences) network, which act as powerful incubators of young talents. Yet pathfinding for young bright minds is still very much dependent on training at foreign institutions.

There are also many other places in the continent where no obvious progress is taking place and which are not catching up. In addition, as in other parts of the world, there is some disaffection for fundamental sciences. All in all, the continent is moving at an uneven pace towards improving in physics and astronomy. However, there are an increasing number of bright spots, which call for strong international support.

\section{Medical physics in Africa}

Francis Hasford Medical physicists (MPs) apply physics concepts for the diagnosis of human diseases through medical imaging and treatment of the conditions through radiation therapy. We predominantly work in clinical, research and development and academic fields.

Medical physics in Africa faces peculiar challenges, foremost of which is lack of recognition of the profession and appreciation of MPs' roles in most African countries. Africa has 1,040 MPs, unevenly distributed among a population of 1.3 billion in the region. It has the smallest number of MPs per million inhabitants globally. The highest concentrations of radio-diagnostic and radiation therapy facilities are in South Africa and northern sectors of the region. Half of African countries have no radiotherapy facilities, creating limited access to radiotherapy cancer care. Other challenges are inadequate numbers of academic and clinical training centres, and lack of job posts.

\section{The contributors}

Rabia Salihu Sa'id is a full professor of Atmospheric Physics at Bayero University, Kano, in Nigeria. She holds a PhD, MSc and BSc in Physics and an MSc in Environment and Development, and is an expert in the effects of dust aerosols on climate and air quality measurements. In 2015, she received the OWSD (Organization for Women in Science for the Developing World)/TWAS (The World Academy of Sciences)/Elsevier Foundation Award for Early Career (Physics), which rewards and encourages women working and living in developing countries who are in the early stages of their scientific careers, having often overcome great challenges to achieve research excellence.

Ibiyinka Fuwape has been a professor of physics at the Federal University of Technology, Akure, Nigeria since 1989. She is currently the Vice Chancellor of the Michael and Cecilia Ibru University, Agbarha-Otor, Delta State, Nigeria. Her research interests include theory of chaos and application of nonlinear dynamics in coupled oscillator systems, neuronal systems, and lower and upper atmospheric research. She is an alumna of the Schlumberger Faculty of the Future Fellowship programme.

Alain Moise Dikandé (full professor in physics) is Head of the Physics Department, Faculty of Science, University of Buea, Cameroon. He is an Alexander von Humboldt Fellow in the 'Experienced Researchers' Category, a Senior Associate of the Abdus Salam International Centre for Theoretical Physics (ICTP, Trieste, Italy), guest editor of the special issue of the Journal of the Optical Society of America (JOSA A and B): Optics in Africa and member of the editorial board of Journal of Optics.

Jamal Mimouni is an Algerian astrophysicist, who received his higher education between Algiers University and the United States ( $\mathrm{PhD}$ in Particle Physics in 1985, University of Pennsylvania). He is the head of a graduate programme in astrophysics at Constantine 1 University in Algeria, and the President of the African Astronomical Society. $\mathrm{He}$ is an active participant in the debate on science and society in the Arab-Muslim World.

Francis Hasford is the Head of Medical Physics at the University of Ghana and Ghana Atomic Energy Commission, Secretary General of the Federation of African Medical Physics Organizations, expert medical physicist for the International Atomic Energy Agency and member of the IOMP (International Organization for Medical Physics) Web Sub-committee. He received his PhD from the University of Ghana and is an associate of the International Centre for Theoretical Physics. $\mathrm{He}$ is the recipient of the 2016 International Union of Pure and Applied Physics (IUPAP)/IOMP Young Scientist Award in Medical Physics.

Delia Haynes did her PhD at Trinity Hall at the University of Cambridge, followed by a postdoctoral fellowship with the Pfizer Institute for Pharmaceutical Materials Science, also at Cambridge. She has been at Stellenbosch University since 2007, where she is now a professor in the Department of Chemistry and Polymer Science. Delia is the chair of the Steering Committee to form the African Crystallographic Association. Irvy (Igle) Gledhill spent time at the University of California, Los Angeles and Stanford before moving to the Council for Scientific and Industrial Research in South Africa, her home country. She is now Visiting Professor of Flow Physics at the University of the Witwatersrand. She is a past president of the South African Institute of Physics and a Vice-President of the Network of African Science Academies. She edits African Physics Newsletter.

George Amolo is a professor of physics and Director of the School of Physics and Earth Science, The Technical University of Kenya, Nairobi, and a research associate in Computational Modelling and Materials Science with the Kenya Education Network (KENET). He received his PhD from the University of the Witwatersrand, South Africa, and worked in the University of Eldoret and Moi University, Eldoret, Kenya, before moving to the Technical University of Kenya in 2016.

Omololu Akin-Ojo received his BSc and MSc Physics degrees from the University of Ibadan, and his PhD from the University of Delaware (USA). Following two postdoctoral stints at Boston University and the Abdus Salam International Centre for Theoretical Physics (ICTP) Trieste, Italy, he returned to Africa - first to Nigeria and now Rwanda as Director of the East African Institute for Fundamental Research, a physics training and research hub. His main research interest is in condensed matter physics and its applications for African development and advancement. Nashwa Eassa is an associate professor of physics and the Dean of the Deanship of Scientific Research at AI Neelain University. She undertook a postdoctoral fellowship in the Nanophotonics group at Nelson Mandela Metropolitan University (NMMU), South Africa. She holds a PhD in physics from NMMU and Master of Science in material physics and nanotechnology from Linköping University, Sweden. 
Available opportunities include the existence of FAMPO (the Federation of African Medical Physics Organizations), the regional medical physics federation. FAMPO is working with member states towards improving quality of service to patients, promoting professional practice of MPs through accreditation and certification schemes, promoting publication of medical physics research findings and uniting the MP workforce regionally. Other opportunities comprise leveraging on fora like Medical Physics Day and partnerships with IAEA (the International Atomic Energy Agency), IOMP (the International Organization for Medical Physics) and others to improve training and general awareness for the profession.

\section{Developing experimental infrastructure Delia Haynes For experimental} scientists like crystallographers, one of the biggest challenges in Africa is access to infrastructure. Instrumentation is often old and dysfunctional, there is little financial support, and access to reliable power and water can be an issue. When equipment is available, there may not be a trained technician, which is a problem when instruments break down - there is no way of getting them fixed. There are also challenges with travel and visas within Africa, a real hindrance to scientists trying to collaborate with their colleagues on the continent. As a result of these challenges with equipment and travel, many African crystallographers must rely on collaborators outside Africa for data.

However, Africa has incredible opportunities for science. The continent has the world's youngest population, and our young scientists are full of energy, enthusiasm and talent. They are driving the formation of scientific societies such as AfCA (the African Crystallographic Association). There is great scope for the development of large-scale research infrastructure, exemplified by the SKA. The African Lightsource Foundation is also working to establish an advanced lightsource on the African continent. Projects of this nature require cooperation between scientists, governments and industry, which is both a challenge and an opportunity!

\section{African physicists are resilient}

Igle Gledhill In Africa, we share the deepest aspirations of all physicists: to discover the basic principles that govern the Universe, and to solve problems and innovate.

Many of our circumstances look intractable. It's not just that internet access is inadequate, but electricity supplies are unstable. In spite of that, the Kenyan research and education network hosted 20 times as many participants in meetings and webinars in June as it did in April.

African physicists can easily feel isolated. Being fully recognized in a global project is one way of changing this: CERN partnerships mean that Africans are in the team at the Higgs scale of achievement. Radio astronomers are deeply engaged with the SKA telescope in nine African countries.

Partnerships inside Africa are also deeply important to us. With much encouragement, electronic structure methods and

applications have taken off; optics, materials science and solar energy consortia have been formed, and fundamental physics has been flourishing. The community is working towards an African lightsource.

Because experimental facilities are expensive to install and maintain, theoretical and computational physics is a great fit for Africa, and it links straight into biophysics and data sciences. The community has risen up to fight COVID-19 with data handling and modelling, pooled testing and ventilator manufacture.

Big problems remain. One glaring example is climate change, but African domain experts are now establishing the first Africa-based Earth Systems Model. Cultural barriers to girls and women entering physics are another battle. The biggest barrier to every effort in Africa is funding, but I'm amazed at how resilient and inventive physicists are.

\section{Physics for development \\ George Amolo In many parts of Africa,} physics is, surprisingly to me, not viewed as a discipline that has a short- or even medium-term impact compared with priority areas such as health, food security, energy and water quality, and water access. As a result, little or no funding is provided for capacity development in the discipline, thus leading to limited research infrastructure. Owing to limited human capacity in physics, considerable time is used in administration and servicing other degree programmes in the natural and applied sciences at the undergraduate level, leaving little time for engagement in quality research work.

There is a need to align research in physics to support national agendas towards human, environmental and socio-economic development in order to remain relevant and benefit from continual local funding. Revised curricula and skills that support areas of discipline application such as medical physics, materials science and renewable energy are examples that should be strengthened. Human capacity development in medical physics will better support the efforts by African governments that annually dedicate large resources of their national budgets to attend to the health needs of their citizens against communicable and non-communicable diseases. Modern technologies used in agriculture, such as greenhouses, moisture content monitors and irrigation, just to mention a few, are well founded in the principles of physics and could be customized through innovation to better serve the citizens. The exploitation of the abundance of energy from the Sun and wind energy has the potential that can reduce the continued use of fossil fuels and destruction of forest to provide domestic needs, thus promoting a safer environment.

\section{Physics for African advancement Omololu Akin-Ojo Physics is vital for} Africa in the building of structures: roads, hospitals, aqueducts, electricity grids, mechanized agriculture plants, food storage facilities, biotechnology laboratories, defence equipment and many more. At this point in history, we can skip most of the trial and error of development and build by adopting and adapting working technologies and know-how from different parts of the world. Large multidisciplinary teams, composed of people with diverse knowledge and expertise from all over the globe, should work together in physics-based science and technology to solve problems in Africa. For example, to mitigate the global water shortage problem, African researchers with colleagues from all over the world are working on water prospecting and mapping of aquifers. Indeed, geophysical prospecting is an important example of the contribution of physics to African development and advancement.

Why do we not see greater impact of physicists in African development and advancement? First, there is a shortage of rigorous academic training and preparation, high-quality mentorship, strong research groups and international collaboration. Second, there is a lack of funding and funding policies. African governments not only need to fund science and technology but must have a policy and vision for science and technology. Training in science and technology should be seen as a means to improve the economy, not as a drain on the economy.

\section{Ways to strengthen physics in Africa}

Nashwa Eassa Many African governments and the industrial sector in African countries do not pay sufficient attention to research in the fields of basic and applied physics, in terms of funding and the use of research 
findings. This situation is due to a limited ability to recognize research in physics as a priority and appreciate its role in developing technologies that may lead to economic growth and sustainable development. Because this situation is ongoing, the research environment is often poor, and researchers have been limited in developing the skills they need to produce distinct research at African research institutions. Therefore, promoting research in physics in African countries is a necessity.

There is also a need to strengthen the research capacity in conducting, managing and sharing research results, besides developing the research environment. Another action that could be taken is to use research outcomes and results to advise policy-makers through policy briefs on topics such as the use of solar energy, knowing that sunlight is available, and there is a shortage in electricity supply in many African countries. Advocacy for science-based evidence to inform decision-making processes is very important and should also include extra mobilization of resources for research within universities in African countries. Universities should formulate interdisciplinary research groups and strengthen collaborative research projects with the private sector and non-governmental organizations to secure funding and ensure the use of research findings. Finally, it is vital to strengthen the research impact at the national, regional and international levels, through publications, evidence-based policies and engagement with stakeholders.

Rabia Salihu Sa'id (D) ${ }^{1 凶}$, Ibiyinka Fuwape $e^{2,3 凶}$, Alain Moise Dikandé iD ${ }^{4 \times}$, Jamal Mimouni ${ }^{4 \times}$, Francis Hasford (iD ${ }^{6 \times}$, Delia Haynes (iD ${ }^{7 \times}$, Igle Gledhill iD ${ }^{8 \otimes}{ }^{\otimes}$, George Amolo iD ${ }^{9 凶}$, Omololu Akin-Ojo ${ }^{10 \otimes}$ and Nashwa Eassa ${ }^{11}$

'Bayero University, Kano, Nigeria.

${ }^{2}$ Federal University of Technology, Akure, Nigeria.

${ }^{3}$ Michael and Cecilia Ibru University, Agbarha-Otor, Nigeria.

${ }^{4}$ Physics Department, Faculty of Science, University of Buea, Buea, Cameroon.
${ }^{5}$ University of Constantine 1, Constantine, Algeria.

${ }^{6}$ Medical Physics Department, School of Nuclear and Allied Sciences, University of Ghana, Accra, Ghana.

${ }^{7}$ Department of Chemistry and Polymer Science, Stellenbosch University, Stellenbosch, South Africa.

${ }^{8}$ Flow Research Unit, University of the Witwatersrand, Witwatersrand, South Africa.

${ }^{9}$ School of Physics and Earth Science, The Technical University of Kenya, Nairobi, Kenya.

${ }^{10}$ East Africa Institute for Fundamental Research (EAIFR), University of Rwanda, Kigali, Rwanda.

${ }^{11}$ Al Neelain University, Khartoum, Sudan.

凶e-mail: rabisalihu@gmail.com; yfuwape@yahoo.com; dikande.alain@ubuea.cm; jamalmimouni@umc.edu.dz; fhasford@ug.edu.gh; dhaynes@sun.ac.za; Igle.Gledhill@ wits.ac.za; georgeamolo862@gmail.com; oakinojo@ eaifr.org; nash.eassa@gmail.com

https://doi.org/10.1038/s42254-020-0239-8

Published online 18 September 2020

Competing interests

The authors declare no competing interests.

Publisher's note

Springer Nature remains neutral with regard to jurisdictional claims in published maps and institutional affiliations.

(C) Springer Nature Limited 2020 